\title{
New Directions in the Sociology of Tourism
}

Please refer to the definitive version of this article when citing:

Cohen, S.A. \& Cohen, E. (2017). New directions in the sociology of tourism. Current Issues in Tourism (In press).

\begin{abstract}
This review article starts with an examination of the shifting nature of tourism discourse from the 1960s up to the present, and then focuses on seven topics that we consider to be on the forefront of current developments in the sociological study of tourism: emotions, sensory experiences, materialities, gender, ethics, authentication and the philosophical groundings of tourism theories. We find that in recent years the sociology of tourism was marked by three general trends: the growing application of specific novel theories from other fields to tourism, the examination of new facets of touristic phenomena, and an intensified inquiry into the status of tourism as an intellectual or cultural project. We conclude that while the application of a range of novel theoretical perspectives and facets largely reflects the postmodern move away from binary thinking and concepts, the sociology of tourism still makes little contribution back to the discipline of sociology, and will need to address important emergent topics such as deglobalization and current nationalistic movements toward isolationism, to do so.
\end{abstract}

Keywords: sociology of tourism, binaries, emotions, sensory experiences, materialities, gender, ethics, authentication, philosophical groundings

\subsection{Introduction}

Contemporary sociology is highly diversified in terms of its philosophical premises, theoretical preferences and empirical priorities. It is marked by a tendency to move from seeking 'truths' to emphasizing perspectives, from conceptualizing bounded entities to stressing the dissolution of their boundaries, and from seeking the principles of social order to studying social transformations. Consequently, concepts like secularization, pluralization, globalization, mobilities and hybridity, and topics such as migration, travel, and, recently, tourism, moved increasingly into the center of sociological interest, together with the recognition of previously marginal topics, such as gender, sexuality, emergent sub-cultures and spirituality. Notably, however, most recent global developments seem to revert attention to possible reversals in the currently stressed trends, toward deglobalization and the re-emergence of right-wing isolationism in advanced industrial societies.

Reflecting some of these trends and topics in the discipline of sociology, the sociological study of tourism has never been more diverse or rich than it is today. While a limited number of theoretical perspectives, such as authenticity and the tourist gaze, and the creation of modernist typologies, dominated earlier decades, tourism is now analyzed and understood from a much broader array of modernist and postmodernist perspectives that increasingly reflects the depth and richness of sociology more generally. The opening up of tourism to wider sociological analysis is at least partly due to the growing acceptance among scholars that tourism is a central 
constituent of contemporary social life, rather than a bounded off or discrete activity (Franklin \& Crang 2001).

Not only are approaches to the analysis of tourism changing, but the nature of the tourism industry is rapidly changing as well. Tourism has undergone a major recent shift in the point of origin of tourists (Cohen \& Cohen 2015a). Whereas most international tourists used to be Westerners, leading to a Euro- or Anglo-centrist bias in early tourism theorizing (Cohen \& Cohen 2015b; Winter 2009), tourists hail increasingly from the middle classes of the world's emerging regions, particularly Asia, a trend with important theoretical and comparative implications for the sociological study of tourism. Furthermore, tourism also reflects ongoing global social changes, ranging from the rise of social networking technologies and the sharing economy (Germann Molz 2013) to 'selfie' culture (Dinhopl \& Gretzel 2016).

This article discusses the key milestones and changing directions in the discourse of the sociology of tourism since it became a field of theoretical controversy in the 1960s. We review the shifting nature of tourism discourse up to the present, including the recent turn in tourism theorizing away from binary concepts, and then turn to seven topics, which we consider to be on the forefront of current developments in the sociological study of tourism: emotions, sensory experiences, materialities, gender, ethics, authentication and the philosophical groundings of tourism theories. Our aim in this article is to give our own interpretation of the most recent theoretical developments and cutting edge topics in the sociological study of tourism.

Methodologically, our literature review is framed in terms of a 'narrative discussion,' an approach which allows for consolidation, summation and identification of gaps (Grant \& Booth 2009). The article thus follows others who have used 'organic, creative and interpretive approaches to conducting reviews of complex literature' as opposed to the rationalist 'frame offered by conventional systematic review methodology' (Dixon-Woods et al. 2006a: 38). As we avoid the systematicity of a more structured approach, our review is consequently subjectively biased by our world views, not comprehensive and should not be viewed as an end in itself (Grant \& Booth 2009). We relied on our own expertise in identifying both the key studies that have influenced the historical discourse on tourism and the leading topics bearing on the current directions of research in the sociological study of tourism. Articles within the latter field were selected on the basis of their apparent relevancy (Dixon-Woods et al. 2006b), without a comprehensive search, appraised without formal rules of quality assessment and evaluated according to our own analysis of their contribution (Grant \& Booth 2009). Though our focus is sociological, we take account of sociologically relevant knowledge on tourism constructed in a range of other fields, especially geography, business studies and psychology. Our discussion is centered primarily on articles published since our review article 'Current Sociological Theories and Issues in Tourism' (Cohen \& Cohen 2012a). The present article thus provides insight into some of the most recent innovative studies offering novel perspectives in the sociological interpretation of tourism.

\subsection{Historical milestones in the discourse of the sociology of tourism}

Since the sociology of tourism became a field of theoretical controversy in the 1960 s, there have been a number of key milestones in tourism scholarship that have affected the discourse of tourism. Our discussion of these is mostly, but not entirely, chronological, as our primary 
aim is to show how changing approaches shifted the focus of discourse, rather than follow a strict chronology.

Boorstin's (1964) exegesis of tourism as a denigration of travel was the earliest theoretically relevant discourse: he lamented the growth of mass tourism, which he largely attributed to technological developments such as the railway, and characterized tourists as a growing body of 'cultural dopes' satisfied by contrived 'pseudo-events'. In contrast, MacCannell's (1973) uplifted tourism by arguing that alienated modern tourists are motivated by a quest for authenticity, which they hope to discover in other times and places, where they could retrieve the experience of a wholeness that has been shattered by an anomic, unstable and inauthentic modernity. But MacCannell $(1973 ; 1976)$ alleged that their quest is thwarted by the 'staged authenticity' offered by their hosts. In the wake of MacCannell's work, 'authenticity' became a key concept in the sociological study of tourism.

As opposed to treating tourists as a homogeneous mass, Erik Cohen (1972) offered a typology of tourists on a familiarity-strangeness scale, ranging from 'organized mass tourist' to 'drifter'. Further plurality was added to the literature through his proposal of a phenomenological typology of modes of tourist experiences: recreational, diversionary, experiential, experimental and existential modes (E. Cohen 1979). This served to disrupt a false binary that had evolved in the literature between the view of the tourist experience as spurious and superficial or as a serious quest for authenticity.

Early conceptualizations of the role of authenticity in tourism motivation had viewed authenticity as objective, static and fixed. This assumption was challenged by the notion of 'emergent authenticity' (E. Cohen 1988), and further qualified by Bruner (1994), who approached authenticity from a constructivist position, and argued that there was no clear distinction between 'originals' and 'copies'. Further complexity has been added by Wang (1999), who offered a distinction between three types of authenticity: objective, constructive and existential. 'Objective' authenticity is taken from museum terminology (Wang 1999), where it is used to determine whether objects are genuine, real or unique. Constructive authenticity is emergent and socially constructed, engendered by interpretations of the genuineness of a toured object, including toured 'Others' (Reisinger \& Steiner 2006; Wang 1999). Existential authenticity was conceived by Wang (1999) as the experience of one's 'true self'. Recent work on existential authenticity, building on Wang's (ibid) is shifting the discourse from 'objective' to a more 'subjective' concept of authenticity; this is discussed further in section 4.7, whereas the recent trend away from questions of what is authentic to the politics of the social production of authenticity, or 'authentication', is discussed in section 4.6.

Positing that the dominant mode of tourism is 'sightseeing,' MacCannell (1976) pioneered the prioritization of the ocular sense in tourism theory, which was significantly amplified by Urry's 1990 introduction of the concept of the 'tourist gaze'. Adapted from Foucault's (1976) medical gaze, wherein doctors gaze on the body to penetrate beneath the body's surface, Urry's 'tourist gaze' perpetuated the power of ocular-centrism in tourism theory by focusing on the visual consumption of tourism landscapes and on the way the gaze is socially organized and systematized.

The sociology of tourism underwent some major changes from the late ' 90 s onwards. First Edensor (1998) conceived of tourism as performance: he looked at the diverse ways in which the Taj Mahal is represented through tourist practices, using the metaphor of tourist sites as a 
stage in which space is organized through performances that include practices of rehearsal and improvisation. This was followed by another major milestone, Franklin and Crang's critique of tourism theories (2001: 6-7) in the inaugural editorial of Tourist Studies, in which they argued that tourism can no longer be conceived as an exotic and bounded activity: 'tourism has broken away from its beginnings as a relatively minor and ephemeral ritual of modern national life to become a significant modality through which transnational modern life is organized'. This de-differentiation of tourism from everyday life (Uriely 2005) made tourism accessible to analysis through some general theoretical approaches in sociology (e.g. performance a la Edensor and others to be discussed below).

The theme of de-differentiation was further advanced by the inclusion of tourism as a mode within the wider conceptual framework of mobilities (Urry 2000), interwoven with other types of mobility, in contrast to the perception of tourism as a distinct extraordinary practice, disentangled from and contrasting everyday life (Cohen \& Cohen 2015a; Hannam, Sheller \& Urry 2006). Even as a discourse of 'tourism mobilities' was consolidated in the literature (e.g. Hannam, Butler \& Paris 2014), critics of a mobilities turn bemoaned that 'framing the world within a single holistic discourse of mobility places limits on the diversity of language(s) and concepts needed to articulate the variegated experiences, understandings, and possible futures that give texture to the fabric of the social world' (Doering \& Duncan 2016: 52). While the perspective of mobilities studies has no doubt permeated the vocabulary of many current tourism researchers, the extent to which a suggested paradigm shift to mobilities in the study of tourism (proposed by Cohen and Cohen [2015b]) will actually take place, is not yet clear (Coles 2015).

The most recent milestone in the sociological discourse of tourism is the turn to theoretical perspectives that reflect 'the post-modern tendency to stress the de-differentiation between social domains, the break-down of conventional binary concepts' and a 'change of emphasis from permanence to flux, from being to doing' (Cohen \& Cohen 2012a: 2180). This is reflected in the mobilities approach, but also in the growing number of studies using Actor-Network Theory (ANT) in tourism research (Beard, Scarles \& Tribe 2016). A related theoretical development is the growing prominence of the performativity approach in the discourse of tourism. The 'performative turn in tourism' has been linked to embodiment: Rickly-Boyd, Knudsen, Braverman and Metro-Roland (2014: 87) observed that this turn directs attention away from the prevailing focus 'on the visuality of tourism to attend to the role of the body, sensuous encounters, emotionality, and affect in tourism...tourism is about more than seeing or gazing, but also concerns the embodied practices that perform places, in which sightseeing may be but one performance'. These three theoretical approaches, mobilities, ANT and performativity, have been identified by Cohen \& Cohen (2012a) as inter-related perspectives, which at the early 2010s as yet found 'few followers' in tourism studies. In the following section we appraise the extent to which such theoretical approaches have achieved growing prominence in tourism research in the last five years.

\subsection{The rejection of binaries in theorizing tourism}

The sociology of tourism has been increasingly influenced in the last five years by the postmodern tendency to de-differentiate binaries, and particularly to reject structuralist dichotomies or binary oppositions as a means of understanding the social world (Appignanesi, 
Garratt, Sardar \& Curry 2004). Binaries have been posited as forming the 'hidden structure' of the social; instead 'postmodernism resists closure and explores the interconnection of opposites' (Sim 2011: 87). Researchers maintain that the complexity and heterogeneity of contemporary society cannot be captured by traditional binaries. A postmodern Lyotardian (1979) view sees binaries as false and oppressive authoritarian forces that silence diversity and conflict (Sim 2011). It is alleged that binaries (e.g. home/away, leisure/work) are particularly problematic when 'a term is used as the opposite of another as a means of creating controversial boundaries among them' (de Souza Bispo 2016: 172).

While tourism studies have stressed for nearly two decades that the heterogeneity of tourism defies stable or single representations (Edensor 1998; Franklin and Crang 2001), and that the field requires pluralizing rather than generalizing conceptualizations (Uriely 1995), the sociology of tourism has only recently experienced a critical mass of researchers employing theoretical perspectives equipped to deal with this heterogeneity, such as the mobilities approach, ANT, performativity, and most recently, practice theories. All of these approaches reject binaries: mobilities break down the borders, for instance, between leisure travel and other flows, such as those of migration and work (S. Cohen, Duncan \& Thulemark 2015); ANT denies a human/non-human dualism, and alleges objects have agency (Jóhannesson 2005); performativity avoids the long-problematic structure/actor divide (Bell 2008), as do practice theories, which require a shift in perspective from dualisms to the complexities of a plenum (de Souza Bispo 2016).

Practice theories embrace several theoretical approaches (Nicolini 2012) cognate to performativity, ANT and mobilities, which posit that the social is to be understood through shared practical understandings (Schatzki, Cetina \& von Savigny 2001). Practice theories allege a flat social ontology, which rejects an agency-structure dualism (Lamers, van der Duim \& Spaargaren 2017). Few studies have employed practice theories in tourism research to date: for instance, Luzecka (2016) uses a social practices perspective to move the discourse on sustainable travel behaviour beyond a structure/agency impasse; Rantala (2010) analyzes through practice theory how the forest is produced as an environment befitting the tourism industry; Bargeman, Richards and Govers (2016) employ a practice approach to investigate the complex impacts of volunteer tourism in Ghana. Tourism studies adopting a practice perspective have tended to treat it as a single theory (for an exception see Lamers et al. [2017] on the application of practice theories to Arctic expedition cruising), and have yet to draw upon the wider range of practice theories, such as 'science and technology studies' and 'communities of practice', recently summarized by de Souza Bispo (2016). Although practice theories have the potential to render significant new insights in tourism research, and seem to be part of tourism's ongoing theoretical 'catch-up' with the social sciences, tourism researchers adopting practice theories must take care not to do so simplistically. Practice theories are based on the assumption of mutual understanding between human actors of social practices (Barnes 2001), which is a pre-condition for the habitualization of practices, which cannot be taken for granted in cross-cultural touristic situations. This highlights issues of contestation and breakdown in the performance of practices in tourism, which are perhaps less salient for practice theoreticians in other fields. The creation of such mutual understanding in cross-cultural situations has still to be explored by practice theoreticians.

In the five years since the publication of Cohen and Cohen's (2012a) review paper, the application of such theoretical perspectives as mobilities, ANT or performativity in tourism 
has moved from the margins towards the center, as the number of studies of tourism adopting these perspectives has steadily grown (cf. Beard et al. 2016; Hannam et al. 2014; Harwood \& El-Manstrly 2012). Few attempts have been made to use several of the theoretical frameworks of mobilities, ANT, performativity, or practice theories, conjointly. A consequence has been that the similarities between these approaches has been under-appreciated in tourism studies, a point to which de Souza Bispo (2016) recently drew attention. Though we disagree with de Souza Bispo's (2016) attempts to subsume all of these approaches under the umbrella of practice theories, we appreciate attempts to articulate their commonalities.

All these theoretical approaches attempt, in diverse ways, to destabilize the modernist assumptions of leading theories in the field; whether this will eventually lead to more comprehensive, as well as more nuanced, novel interpretations of tourism has yet to be established.

\subsection{Topics indicating new directions in the sociology of tourism}

The recent theoretical developments discussed above have drawn attention to some new topics in tourism studies. We focus here on seven leading examples: emotions, sensory experiences, materialities, gender, ethics, authentication and the philosophical groundings of tourism theories. The first five topics relate to empirical phenomena that attracted growing attention in recent tourism research, whereas authentication is a specific dynamic process, congenial to the processual, diachronic perspective of contemporary tourism theories; the attempt to clarify the philosophical groundings of tourism theories reflects some more profound implications of the growing tendency to see tourism as integral to contemporary culture, rather than extraneous to it.

\subsection{Emotions}

Cohen and Cohen's (2012a) review has located only a handful of studies focused on emotions and affect in tourism (e.g. Conran 2011; Modlin, Alderman \& Gentry 2011), and called for further sociological accounts on these topics in tourism research. Picard and Robinson's (2012) parallel call, in the first edited book on emotions in tourism research, for an 'emotional turn' in the field, seems to have come to fruition. A recent proliferation of articles on emotions, feelings and affect in tourism suggests a recent rush to address this research area, which can be attributed to at least two developments: one, attempts to overcome disembodied accounts of tourism that view it solely in terms of economic activity, as reflected by the efforts of 'critical tourism scholars' (Tucker 2016); and two, a shift to emotions in consumer behaviour research and in psychological studies of tourist experience, upon the realization of their economic and managerial importance (Tung \& Ritchie 2011). These developments reflect the widening acknowledgement in tourism research that emotions play a crucial role in tourism experiences and encounters, and are therefore important for understanding tourists and the tourism industry, as a complement to the long-accepted role of cognitive processes.

In moving away from disembodied and business-focused accounts of tourism, authors have both turned inwards towards their own emotional entanglements in the research process (Pocock 2015), and outwards towards using understandings of embodied emotions to address 
such issues as social inequalities. The latter draw on Ahmed (2004) to examine how feelings of 'frustration, fascination, anger and shock' in tourism encounters cause tourists and tour guides to feel emotional connections and separations with places (Buda, d'Hauteserre \& Johnston 2014: 107). Buda et al. (ibid: 104) introduce Ahmed's (2004) 'cultural politics of emotion' as a theoretical framework to study issues of power in tourism encounters in Jordan and the West Bank.

Frazer and Waitt (2016) also adopt Ahmed's approach to emotions as a theoretical framework, but draw upon her theorization of pain (2015) to understand the empathic pain experienced by volunteers in their work. Tucker (2016: 32) likewise focuses on empathy in tourism encounters, defining it as 'an emotional capacity to "put oneself into the shoes of another" in order to understand their experiences'. Empathy is linked by Tucker to issues of peace and understanding across cultural divides. She positions empathy as an 'emotional pre-requisite for engaging in positive dialogue with "the other"' (ibid: 40). Though linking empathy to social justice, Tucker (ibid: 39) highlights the risk that empathy might engender a false sense of fully 'knowing' an individual or group, and warns of 'lazy empathy', which 'does not involve challenging the self'. The works of Frazer and Wait (2016) and of Tucker (2016) are more attenuated to questions of what empathic pain and empathy $d o$, or to their consequences, rather than their meanings. Like Buda et al. (2014), they are consequently concerned with the politics of emotions; hence their work can be viewed as akin to the agenda of the critical turn in tourism studies (Ateljevic, Morgan \& Pritchard 2012).

Studies concerned with emotions and social justice, such as the above, have adopted 'tourism encounters' as their unit of analysis; in contrast, psychological and consumer behaviour research, which is interrelated with sociological perspectives, considers emotions in the context of 'tourist experience'. Studies of tourist emotions with a consumer behaviour/management focus have proliferated, taking their starting point in psychology and affective neuroscience (e.g. Pearce 2012). The role of emotions in tourists' experiences is acknowledged as important to both academics and industry managers ( $\mathrm{Li}, \mathrm{Scott}$ and Walters 2015), and has been explored, for instance, in studies of the preferable color of hotel rooms (green) for the 'emotional wellness' of guests (Lee, Guillet \& Law 2016), and of 'delight' as an emotion to be leveraged in designing tourism experiences (Ma, Gao, Scott \& Ding 2013). But studies of emotions in tourist experiences tend to neglect and disempower the emotions of a varied range of stakeholders, who play the role of 'hosts' in tourist encounters.

\subsection{Sensory experiences}

From its inception, tourism featured an ocular-centric (Rakić \& Chambers 2012) bias, an Occidentalist (Agapito, Mendes \& Valle 2013) prioritization of the sense of sight over the other senses. 'Sightseeing' was often unreflectively perceived as the typical tourist activity, while in German the term 'Sehenswürdigkeiten' (things worth seeing') was used for 'attractions'. Urry's (1990) The Tourist Gaze gave the prioritization of the ocular a theoretical underpinning. The role of the other senses in tourism was neglected in tourism studies, and remained undertheorized and under-researched up to the early 21 st century. This neglect led to an implicit image of the tourist as a passive observer, rather than an agent actively engaged with all her/his senses with the physical and social environment. The study of the senses, beyond the ocular, is intended to make up for this deficiency. 
Following the recent rise of 'sensory studies' (Vaninni, Waskul \& Gottschalk 2011), market researchers examined the role of the sensory apparatus in the consumer's experience. Hultén (2011: 257-258), writing about the 'emotional experience associated with a service brand', argued that the marketing literature neglected the human senses, and proposed the concept of a multi-sensory brand-experience, involving the senses of smell, sound, sight, taste, and touch. A similar argument could be made with respect to the tourism literature: it was only recently that a growing number of researchers began drawing attention to the role of different senses in the tourist experience (e.g. Jacobsen 2014; Masson 2016).

Most sensory tourism researchers embraced the conventional division and hierarchy of the external senses, sight, followed by hearing, smell, taste and touch, attributed to the Greek philosopher Aristotle. Neuroscience has recently proposed additional sensory signals, mostly originating from within the body, classified as the proprioceptive sense (which, together with the vestibular sense [sense of balance], gives rise to kinaesthesia, the sense of movement), the visceral sense and the sense of pain and temperature (Agapito et al. 2013); some of these have been included in the list of senses by tourism researchers (e.g. Kim \& Fesenmaier 2015).The boundaries between sensory tourism studies and the study of affects (d'Heuteserre 2015) and emotions (Picard and Robinson 2012) in tourism are fuzzy.

Tourism sensory studies focus on the various sensory experiences encountered by tourists in the course of a trip, but also touch upon activities focused on a particular sense, such as music festivals (sound), gastronomy (taste) and wellness services (smell and touch), which are also the subject of specialized fields of study, such as musicology, food studies and wellness studies. Sensuality, a highly significant component of the tourist experience, straddling the boundary between senses and emotions, is a somewhat neglected topic (Pritchard, Morgan, Ateljevic \& Harris 2007; Pritchard \& Morgan 2011), though one of its modalities, sex in tourism, has gained increasing attention (Carr 2016).

The study of sensory experiences of tourists is in principle an interdisciplinary field, but is in fact dominated by psychological approaches, particularly in marketing (Agapito et al. 2013; Kim \& Fesenmaier 2015) and destination branding studies. Sensory studies by tourism researchers share some common traits: they prioritize the embodiment paradigm over the cognitive paradigm (Agapto et al. 2013); propose various 'scapes' for specific senses such as soundscapes (Liu, Liu \& Deng 2016), smellscapes (Dann \& Jacobsen 2003), tastescapes (Quan \&Wang 2004), thermalscapes (Jensen, Scarles \& S. Cohen 2015) and hapticscapes ('touchscapes'); but many prefer a holistic, multi-sensory approach over the study of specific senses (Agapito et al. 2013; Hultén 2011; Jensen et al. 2015). However, while rich in conceptualizations, the field of sensory studies in tourism is still quite poor in concrete empirical research. Among recent examples of such research are Agapito, Valle and Mendes' (2014) holistic study of the sensory dimension in the experiences of tourists to Southwest Portugal; Griggio's (2015) study of the encounter between visitors and moose in a park as a multi-sensual event; Matteucci and Filep's (2015) study of a flamenco course for tourists as an embodied musical and dance experience; and Jensen et al.'s (2015) study of interrail mobilities. The study of tourists with sensory disabilities (e.g. Dann \& Dann 2012; Masson 2016; Small, Darcy \& Packer 2012; Jensen 2016) is a significant emerging sub-field of sensory studies in tourism. 


\subsection{Materialities}

In the last five years tourism studies began to pay growing attention to the importance of what are termed 'non-human actors' in producing and maintaining tourism practices, even though there were sharp earlier calls on the tourism academy to do so (e.g. Haldrup \& Larsen 2006; Pons 2003). The study of non-human actors, or materialities, is linked to ANT, as ANT focuses on the processes that 'produce and maintain assemblages of human and non-human actors' (Beard et al. 2016: 98). ANT thus alleges that materialities have a kind of agency. Both ANT and the 'material turn' (Muecke \& Wergin 2014) have roots in Latour's (2005) sociology of associations, wherein the 'social' is 'glued together' by many types of 'connectors', both human and non-human, and is inseparable from the material. Proponents of ANT and materiality insist on 'ontological symmetry' between human and material actors (Jóhannesson 2005; van der Duim, Ren \& Jóhannesson 2017), but since they admit that objects do not 'act' in the same sense as humans, the sense in which objects are ascribed 'agency' in ANT remains obscure.

Haldrup and Larsen (2006: 276) argue that tourism studies 'have failed to understand the significance of materiality and objects in modern tourism,' and that the field has reduced things and places to just their sign-value, or what they represent. Social and cultural life is in contrast enabled in intricate ways by non-human actors, reflecting the 'hybridity' of non-human and human worlds (Haldrup and Larsen 2006). It has therefore been important for the sociological interpretation of tourism to relinquish its historical human-centric focus, as the study of materialities in tourism can allow for more complex understandings of how tourism practices are produced.

A recent special issue in the journal Tourist Studies themed 'Materialities of Tourism' (Muecke $\&$ Wergin 2014) has to our knowledge been the first collection of papers in the field of tourism to focus on this area. Muecke and Wergin (2014: 228) draw attention to the range of 'material things' that 'have a particular value in the leisure and tourism markets as they are absolutely necessary for human agency and performativity, for example, as souvenirs', or as tools in the mundane everyday practices of mass tourism, such as the bucket and spade at the beach, on which Franklin (2014) focuses in the same special issue. Baldacchino (2010) has been similarly drawn to the beach to study materiality, focusing on the materiality of sand to better understand the fascination with it in the Western imaginary. Studies of sand have explored it in relation to the sense of touch, such as the tactile experiences of building sandcastles and of sunbathing, in further efforts to move away from ocular-centric interpretations of the beach (Pons 2009). While studies of sand or buckets and spades may seem trivial, such examples demonstrate how seemingly mundane everyday objects co-constitute tourism in intricate ways, which are otherwise easy to overlook. Examples of how more obvious materialities such as cars and planes play a role in producing tourism practices remains to be researched.

Gibson (2014: 287) dwells on Texan cowboy boots as a souvenir, providing an 'entry point into questions of morality and materiality, mobility and the value of cultural work'. Gibson (ibid) introduces a novel approach into tourism research, related to studies of material culture in geography that 'follow-the-thing' (Pfaff 2010). Whereas Pfaff (ibid) follows the mobility of a particular mobile phone in Africa, as a window into Swahili cultural and spatial practices, even calling it at times to speak to its changing owners, Gibson (2014: 287) follows Texan 
cowboy boots through archival research that unravels 'a historical cultural economy of material production that entangles animal skins, migrant workers, Western movie stars and tourists.'

The works of Pfaff (2010) and Gibson (2014) have at least two important implications for tourism research. One, studies that physically 'follow-the-thing' in tourism research may render important sociological insights that can provide 'a more complex picture of the material cultures of tourism' (Gibson 2014: 286); there are yet few studies of this kind. A growing body of work that uses tracking technologies to understand tourist mobility (Shoval \& Ahas 2016), has yet to extend to tracking the whereabouts and 'careers' of mundane non-human tourism objects. Two, while Gibson (2014) draws attention to the dead skins of animals as material culture, and positions this as contrasting research on such themes as animal welfare and animal sightseeing, he indirectly uncovers the problematic status of animals in both material studies and those adopting ANT. Both have a tendency to dichotomize human and non-human actors, leaving the status of animals unclear, as they become lumped in with materials and objects. While even animal skins are ascribed agency, and 'continue to have affective power after death' (ibid: 294), live animals seem to lose their status as sentient beings, paradoxically within the very approaches that advocate a post-humanist ontology.

\subsection{Gender}

A recent review article offered a nearly comprehensive update on tourism gender research (1985-2012) by a gender-aware bibilometric analysis (Figueroa-Domecq, Pritchard, SegoviaPérez, Morgan and Villacé-Molinero 2015). Outlining the trajectory of tourism gender research, the authors point to the emergence of research on tourism and gender in the 1980s, and highlight as foundational the special issue on 'Gender in Tourism' in Annals of Tourism Research (cf. Swain 1995).

But Figueroa-Domecq et al. (2015) disregard an important point raised in an early paper by Veijola and Jokinen (1994): the body has been missing from 'universalizing' tourism theories. This is insightfully illustrated through an imagined conversation with John Urry in that paper, from which they conclude that the body has been absent from sociological studies of tourism, at least partly because analyses have tended to focus on the disembodied gaze. The gaze suggests a rationalist focus on the sense of vision, or an ocular-centrism that assumes an abled body, or no body at all, resembling the disembodied smile of Lewis Carroll's Cheshire Cat.

While the study of gender and the body in tourism has gained more attention in recent years, and has become an important area of research, helping to overcome the limitations of earlier tourism theories shaped by disembodied rationalism, few studies in tourism engage with prominent gender theories, or address theoretical issues related to the body in tourism. Even Figueroa-Domecq et al. (2015, p. 97) do not go into detail in their discussion of the relevance of the three major waves of feminist research - feminist empiricism, standpoint feminism and post-structural feminism - for tourism, offering just a sentence or two on each. There is a need for more fine-tuned theoretical critiques and theory-building on gender in tourism research, including catching up in tourism studies with the resurgence of studies on empowerment in the field of gender (e.g Heyes 2007).

There have been several new contributions in tourism gender research since 2012. For instance, Ferguson and Alarcón (2015: 412) call for 'a re-evaluation of the concept of sustainable 
tourism to incorporate gender analysis and gender equality as fundamental components'. The prolific work (more than 10 articles) by Berdychevsky and colleagues on topics such as 'girlfriend getaways' (all-female leisure travel) (e.g. Berdychevsky, Gibson \& Bell 2016) and women's sexual encounters during holidays (e.g. Berdychevsky, Gibson \& Poria 2013) is also notable. Yang, Khoo-Lattimore and Arcodia (2016) have reviewed studies of women's travel experiences and argue that although there has been considerable research on this area, the focus has been mostly on Western women. Their focus on Asian female travelers documents an increasing resistance over time to Asian cultures' conventional gender norms, as expressed for instance by a rise in Taiwanese and Japanese solo female travelers.

Yet as Figueroa-Domecq et al. (2015) imply, gender research in tourism remains largely focused on women, while the study of masculinities is neglected. This may be at least partly due to masculine viewpoints remaining an unobtrusive norm, or being 'hidden in full view' (ibid). There is evidence, however, of emerging studies of masculinity in tourism performances, such as Spracklen, Laurencic and Kenyon's (2013) work on masculine hegemonies in 'real-ale' (beer) tourism at British beer festivals, where gender dimensions intersect with issues of class, 'race' and localism. Finally, to the best of our knowledge there have been few studies applying transgender theories in tourism, despite research on sexualities that point to the sex tourism industry as a site where sex workers may negotiate new thirdgender identities (Ocha \& Earth 2012).

\subsection{Ethics}

Tourism has been frequently criticized from some major ideological perspectives, as a form of imperialism (Nash 1977) or post-colonialism (Echtner \& Prasaf 2003; Hall \& Tucker 2004), and implicitly condemned in terms of such totalizing approaches. However, as Caton (2012: 1096) noted, there was an unfortunate paucity of studies of ethical issues in tourism. Such issues have started to attract the attention of ethicists or of students of tourism only relatively recently. The reason for the late recognition of the importance and relevance of ethical issues in tourism might well be due to some Western attitudes toward tourism, which prevailed in the past: on the one hand, its perception as an unserious (Gibson 2008: 407), superficial activity (e.g. Boorstin 1964), which, resembling play (E. Cohen 1985), is not part of ordinary life with its conventional ethics; and on the other hand its perception as a zone of permissiveness and indulgence, which ought not to be judged by the same ethical criteria as deployed in daily life. Indeed, the issue of ethics in tourism has a paradoxical aspect: the fun and enjoyment, which endows a vacation with its charm, might be antithetical to the moral prescriptions regulating ordinary life (c.f. S. Cohen, Higham \& Reis 2013). Akrasia, the conscious transgression of ethical precepts (Fennell 2015), seems to be intrinsic to many modes of touristic enjoyment.

However, researchers and observers of tourism eventually realized that even frivolous touristic activities can have serious ethical consequences. Starting in the early 2000s, the ethics of tourism became the topic of a growing number of books (e.g. Butcher 2003; Fennell 2006; MacCannell 2011; Mostafanezhad \& Hannam 2014; Weeden \& Boluk 2014), as well as articles examining the ethics of specific sub-fields of tourism.

An assessment of the ethics of tourists and tourism establishments is complicated by the sheer variety of contemporary ethical theories. Thus, Lovelock and Lovelock (2013) discuss the 
ethics of tourism from the perspective of Intuitionism, Teleology, Utilitarianism, Hedonism, Egoism, Deontology, Golden Rule and Social Contract, while Fennell discusses the more limited sub-field of animal ethics in tourism in terms of five animal ethics theories (see summary in Fennell 2015: 28-29). Each of these theories leads to different prescriptions regarding the ethically correct conduct towards animals and the natural environment in tourism.

Since tourism commonly involves encounters between different cultures, the issue of ethics in tourism is further complicated by the problem of cultural relativism, namely 'the doctrine that holds that (at least some) [cultural] variations are exempt from legitimate criticism by outsiders' (Donnelly 1984: 400). Some customs, such as the breaking of young elephants in Thailand (E. Cohen 2015) or bullfighting in Spain (E. Cohen 2014), might be ethically repugnant to visiting (Western) tourists, as an infliction upon animal welfare or rights, but are, or have been up to recently, deeply ingrained in local culture and locally perceived and justified as 'tradition'. Less noted is the issue of cultural relativism regarding the conduct of tourists from varying cultural backgrounds, such as from Asian countries or the Middle East, who might, for example, have different ethical attitudes to the use of animals in performances for tourists, than do many contemporary Western tourists. If local cultural customs ought to be exempted from judgment by outsiders, should the same reasoning apply to the cultural attitudes and conduct of foreign visitors?

The ethics of tourism have been examined at various levels of conceptual abstraction, from concrete issues of practical ethics in the running of tourist establishments to in-depth philosophical deliberations. The works of Knani (2014) and Caton (2012) illustrate these contrasting approaches. Knani (2014) has recently reviewed the various concrete, empirical ethical problems facing the hospitality industry, such as the ethics of front-line employee behaviour and the ethical orientation of managers of hospitality enterprises. But Knani (ibid) writes from an instrumentalist standpoint, common in business studies, which stresses the importance of ethics in hospitality as a means to achieve organizational goals; but he does not question those goals themselves. In contrast, Caton (2012: 1913) relates to ethical issues, which are 'innate to the [tourist] enterprise itself'. Taking an anti-foundationalist philosophical position, Caton embraces a pragmatist 'ethics without ontology,' and explores the ethical difficulties involved in the contrasting goals of individual fulfilment and social responsibility at the heart of contemporary tourism.

While the studies reviewed by Knani (2014) might help to improve the conduct of the staff and management of tourist establishments, it is the ethics of the neoliberal politics of tourism development, especially in the emerging world regions, with its rapid commercialization of nature and local cultures, which needs increased attention in tourism studies.

\subsection{Authentication}

The longstanding inquiry into authenticity by tourism scholars has also shifted attention in the last five years away from the question of 'whether an object, event or site is authentic', and instead to 'who has the authority to authenticate' (Bruner 2005: 150; Lugosi 2016), and the related politics of designating sites or objects as 'authentic'. While there has remained a significant line of research that continues to investigate existential or subjective authenticity (see section 4.7), research into authentication reveals how designations of objective 
authenticity are subject to conflicts of interest, and are thus inherently political and related to power. Drawing attention to the political dimensions of how authenticity is produced leads to a shift of focus of interest to what authenticity does, rather than what it is. This, is important because it uncovers conflicts of interest and issues of power implicit in the authentication process.

Knudsen and Waade (2010) have argued that performativity is crucial to the construction of authenticity, and Noy (2009) has shown how public performances play a constitutive role in authenticating attractions. Building on these perspectives and Xie's (2011) paper on authentication in ethnic tourism, Cohen and Cohen (2012b) proposed two modes of authentication: cool and hot. Cool authentication is frequently granted by 'certification' or 'accreditation', whereas hot authentication depends on performative reinforcement by visitors. The two modes are often not discrete, but rather co-constitutive (ibid).

A number of papers have recently sought to advance conceptual and empirical understandings of authentication. Mkono (2013: 218) uses netnography to empirically substantiate authentication in tourism: she raises questions over who authenticates the authenticator in cool authentication, as there 'could never be an absolute, incontestable expert'. Her conclusion is that both hot and cool authentication are always incomplete. Authentication has furthermore been investigated in the context of sports tourism: Lamont (2014) demonstrates how social media performances, such as the sharing of photos, contributes to the hot authentication of the French Alps as the 'authentic space' of Le Tour de France.

Identifying shortcomings in Cohen and Cohen's (2012b) conceptualization of cool and hot authentication, Frisvoll (2013: 275) argues that the framework is not equipped to deal with 'the origins of what spurs the performative practices and [their] embeddedness with the complex and messy mesh of cultural notions, social representations, materiality, political discourse and practices.' Frisvoll (2013: 294) attempts to rectify this deficiency by focusing on how authenticity is produced at the intersections of social representations, materiality and practice, and emphasizes the role of 'hardware' (i.e. materiality) in the 'multifaceted mesh' of authentication. Lugosi's (2016: 101) recent paper advocates 'a perspective on the study of authentication that accounts more fully for the role of technology in valuing the places, practices and objects entangled in the production and consumption of tourism.' The study employs a socio-technical, 'market-practices' approach that draws on ANT in order to understand authentication as 'the designation, calculation and qualification of worth or value' (ibid: 100-101). Lugosi (2016: 101) shows 'how multiple socio-technological agencies are enrolled in assembling or constructing notions of authenticity', but specifically how 'pervasive computing technology...shape[s] the process of authentication'.

The conceptual basis of authentication has thus recently been furthered by the use of cognate novel theoretical approaches, especially ANT, materiality and performativity (Frisvoll 2013; Lamont 2014; Lugosi 2016). This is complemented by an improved understanding of how contemporary social mechanisms, such as social media, facilitated by mobile technologies (e.g. Lamont 2014; Lugosi 2016), became important performative agents in the social production of authentication, just as 'offerings of votive objects, candles, flowers... graffiti, inscriptions and written supplications presented or left by visitors' (Cohen \& Cohen 2012b: 1299) have been in the past. A remaining challenge is to understand how relatively new material objects, such as 
selfie sticks, become imbricated in embodied processes of hot authentication, both of attractions and of self-identities (c.f. Hooper, Costley \& Friend 2015).

\subsection{Philosophical groundings of tourism theories}

Tourism researchers have conceived the field's relationship to philosophy in many different ways (Tribe 2009). Recent work in tourism has deepened that relationship by (a) integrating philosophical concepts into the development of particular theoretical approaches an (b) seeking to base theoretical approaches on specific philosophies.

(a) Some sociologists have taken recourse to basic philosophical concepts, particularly 'ontology' and 'epistemology' in formulating their theoretical or methodological approaches, while shaping their meaning to serve specific purposes. These efforts have penetrated into theorizing in tourism studies. A highly idiosyncratic use of 'ontology' was recently made by theoreticians of a novel version of ANT, dubbed (post)Actor-Network Theory (Jóhannesson, Ren \& van der Duim 2015), which builds upon Mol's (1999) relativistic view of ontology, according to which 'the reality we live with is one performed in a variety of practices. [Consequently] reality itself is multiple' (Mol 1999: 74); van der Duim et al. (2013: 13) hence posit that 'no real, singular, independent, objective reality exists,' but only different versions of reality produced by various methods, thus in fact collapsing the ontological and the epistemological dimensions of reality. The choice between alternative versions of reality opens the possibility of 'ontological politics' (Mol 1999, Jóhannesson et al. 2015), with variously positioned actors choosing different versions of reality (e.g. Carolan 2004). However, Jóhannesson et al. (2015) declare that they do not intend to develop a new universal theory of tourism, but that their approach only helps to reveal overlooked aspects of touristic phenomena.

(b) Other tourism authors have taken recourse to existential philosophy to establish a philosophical grounding for tourist experiences of 'existential authenticity' (Pons 2003; Wang 1999). Steiner and Reisinger (2006) have been the pioneers in linking tourists' existential experience to the German existential philosopher Martin Heidegger. They state that Heidegger emphasized that the 'existential self is transient,' hence 'one can only be authentic in different situations'; it follows that there are no 'authentic and inauthentic tourists' (ibid: 303). Rather, existential authenticity is a transient experience, as is Cary's (2004) spontaneous 'tourist moment'. More recently, Brown (2013), drawing on Heidegger and Sartre, argued that tourism serves as a catalyst for existential authenticity, while Rickly-Boyd (2012) detected 'moments of existential authenticity' in the experiences of the lifestyle rock climbers, whom she studied.

Shepherd (2015: 64) recently took issue with authors who based their argument on Heidegger's philosophy, such as Steiner and Reisinger (2006), pointing out that, 'according to Heidegger, personal authenticity can only be experienced within a community, where one is literarily at home (and hence not on the road)' and 'emphasized the rootedness of authentic being, precisely the opposite of travel'. Shepherd (ibid: 63) therefore concludes that the 'existential authenticity theory in tourism based on the work of Heidegger...is in fact a misreading'.

Closely related to the discussion of existential authenticity is the recently burgeoning literature on 'transformative travel' (Kirilova, Lehto and Cai 2016; Lean 2012; Lean, Staiff \& Waterson 2014; Reisinger 2015; Robledo \& Batle 2015). In a broad sense, transformative travel refers to the role of travel as an agent of personal (or social) transformation (Lean et al. 2014), in some 
instances leading to far-going changes in an individual's lifeways. Personal transformation has been defined as 'a dynamic, uniquely individualized process of expanding consciousness whereby individuals become critically aware of old and new self-views and choose to integrate these views into a new self-definition' (Holland-Wade 1998: 713). Reisinger (2015) describes the stages of that process, and implies that travel and tourism are one avenue offering such a transformation.

A recent study of existential transformation in tourism (Kirilova et al. 2016) establishes another link between personal transformation and existential philosophy. The authors stress the significance of existential anxiety or Angst, as discussed by existentialist philosophers, as a trigger of the transformation process, and make an important distinction: 'Tourism experiences can facilitate short-lived existential authenticity (Wang 1999), yet to uncover the nature of a truly transformative tourist experience, a nuanced understanding of existential anxiety is needed' (ibid: 4). Existential transformation is thus predicated on an individual's confronting existential anxiety to achieve 'the lifestyle and the state of being that are authentic to one's true values' (ibid: 4). Kirilova et al. (2016) present a detailed study of the process of transformation which individual tourists have experienced in the wake of their travels, thus opening a new avenue of empirical research in tourism studies.

\subsection{Conclusion}

Rather than by general theoretical innovations, the sociological study of tourism in recent years is marked by three specific trends. First, the growing application of specific novel theories from other fields to tourism phenomena: e.g. ANT, performativity, feminist/gender and consumer behaviour theories. Second, the examination of new facets of touristic phenomena: emotions, the body, the senses (beyond ocular-centrism) and materialities. Embodiment, as an approach that overcomes a Cartesian divide between body and mind (Pons 2003), is a major integrative theme across these topics, as well as across gender and authentication. Third, the recent sociology of tourism includes an intensified inquiry into the status of tourism as an intellectual or cultural project, through a focus on ethics and philosophy. Many of these theoretical approaches, such as ANT, performativity and practice theories, and novel topics, such as materialities, emotions and the senses, share the rejection of binary concepts (e.g. structure/agency, body/mind, host/guest, home/away) and thus have ontological commonalities, that is, a tendency towards post-humanistic, non-representational and/or poststructural ontologies, as advanced by postmodernist sociological and philosophical thinkers.

The turns in theorizing and topics that we reviewed in this article contribute to the emergence of novel perspectives on tourism, and thus both complement and criticize previous 'milestone' perspectives. These trends reflect new directions in the sociological interpretation of tourism, which mirror the contemporary emphasis in the discipline of sociology on plurality, the dissolution of bounded entities and social transformation. Though it is not yet clear whether such novel approaches, as, for instance, embodiment and materialities, will eventually supersede previous dominant approaches in the sociological study or tourism, such as the study of authenticity and the tourist gaze, it is undeniable that the range of topics examined in the sociology of tourism has significantly expanded in recent years; particular studies have also added intellectual depth to the field, which was in the past often seen as concerned with frivolous activities. 
But our review indicates that the field still suffers some significant limitations: in particular, even though the sociology of tourism is embracing a range of inter-related theoretical perspectives and topics, it still makes little contribution back to the more general discipline of sociology itself. This is an important and realistic expectation as the scientific significance of a field is often assessed by its contribution to basic theoretical issues, ranging beyond the specific field (e.g. the sociology of scientific knowledge giving rise to ANT). To help overcome this, tourism researchers ought to be increasingly concerned with sociological aspects of the intersections between tourism and broader emergent global issues, such as the aging of the global population, the effects of automatization, climate change and sustainable development, the human expansion into space and the rapid global expansion of urban living. As more than $60 \%$ of the world's population will be living in urban areas by 2050 , the nexus of tourism and urban studies for instance is already becoming an important new research direction (e.g. Dirksmeier \& Helbrecht 2015; Gotham 2005).

Another issue of rapidly growing importance is the effect of de-globalizing tendencies on tourism, as well as tourism's effect on these tendencies, in light of the rise of right-wing populism, the retreat of liberal cosmopolitanism, the tightening of borders and tourism's interlinkages with unwanted ('illegal') migration. These topics to a large extent reflect the despair of those who had been left behind by the rapid processes of globalization and technological change, and have been excluded from the expanding freedom of travel, enjoyed by the privileged strata of their societies. This may indicate a need to desist from over-engagement with ever finer and finer points of postmodernist theories, under the realization that the basic issues of social dynamics, as discussed by Marx and Weber, are still highly relevant even to the sociological study of tourism. Bounded entities, like countries, borders and nationalities, which still mobilize people's emotions, even if they were dissolved by postmodernist theories on mobilities and the death of master narratives, are in resurgence, and could lead to increased suspicion and animosity towards foreigners, which might, among else, also affect tourism. Indeed, if the 'end of tourism' (Urry 1995; Gale 2009) is to come into sight, it now seems that this hyperbolic vision is more likely to transpire under processes of securitization and isolationism, rather than the de-differentiated flows of global capitalism.

\section{References}

Agapito, D. Mendes, J. \& Valle, P. (2013). Exploring the conceptualization of the sensory dimension of tourist experiences. Journal of Destination Marketing \&Management, 2(2), 6273.

Agapito, D., Valle, P. \& Mendes, J. (2014). The sensory dimension of tourist experiences: Capturing meaningful sensory-informed themes in Southwest Portugal. Tourism Management, 42, 224-237.

Ahmed, S. (2004). Collective feelings or, the impressions left by others. Theory, Culture \& Society, 21(2), 25-42.

Ahmed, S. (2015). The cultural politics of emotion. ( $2^{\text {nd }}$ edition). New York: Routledge.

Appignanesi, R., Garratt, C., Sardar, Z. \& Curry, P. (2004) Introducing Postmodernism. Cambridge: Icon Books. 
Ateljevic, I., Morgan, N. \& Pritchard, A. (2012). The critical turn in tourism studies: Creating an academy of hope. New York: Routledge.

Baldacchino, G. (2010). Re-placing materiality: A Western anthropology of sand. Annals of Tourism Research, 37(3), 763-778.

Bargeman, B., Richards, G. \& Govers, E. (2016). Volunteer tourism impacts in Ghana: a practice approach. Current Issues in Tourism, doi: 10.1080/13683500.2015.1137277.

Barnes, B. (2001). Practice as collective action. In T. Schatzki, K. Knorr Cetina, \& E. von Savigny (Eds.), The practice turn in contemporary theory (pp. 25-36), London: Routledge.

London and New York: Routledge.

Beard, L., Scarles, C. \& Tribe, J. (2016). Mess and method: Using ANT in tourism research. Annals of Tourism Research, 60, 97-110.

Bell, E. (2008). Theories of Performance. Los Angeles: Sage.

Berdychevsky, L., Gibson, H.J. \& Bell, H.L. (2016). 'Girlfriend getaway' as a contested term: Discourse analysis. Tourism Management, 55, 106-122.

Berdychevsky, L., Gibson, H. \& Poria, Y. (2013). Women's sexual behavior in tourism: Loosening the bridle. Annals of Tourism Research, 42, 65-86.

Boorstin, D.J. (1964). The image: A guide to pseudo-events in America. New York: Harper \& Row.

Brown, L. (2013). Tourism: A catalyst for existential authenticity. Annals of Tourism Research, 40, 176-190.

Bruner, E.M. (1994). Abraham Lincoln as authentic reproduction: A critique of postmodernism. American Anthropologist, 96, 397-415.

Bruner, E. (2005). Abraham Lincoln as authentic reproduction. In E. Bruner (Ed.), Culture on tour (pp. 145-168). Chicago: University of Chicago Press.

Buda, D.M., d'Hauteserre, A-M. \& Johnston, L. (2014). Feeling and tourism studies. Annals of Tourism Research, 46, 102-114.

Butcher, J. (2003). The moralization of tourism: Sun, sand and saving the world? Abingdon: Routledge.

Carolan, M.S. (2004). Ontological politics: Mapping a complex environmental problem. Environmental Values, 13(4), 497-522.

Carr, N. (2016). Sex in tourism: Reflections and potential future research directions. Tourism Recreation Research, 41(2), 188-198.

Caton, K. (2012). Taking the moral turn in tourism studies. Annals of Tourism Research, 39(4), 1906-1928.

Cohen, E. (1972). Toward a sociology of international tourism. Social Research, 39(1), 164182. 
Cohen, E. (1979). A phenomenology of tourist experiences. Sociology, 13(2), 179-201.

Cohen, E. (1985). Tourism as play. Religion, 15, 291-304.

Cohen, E. (1988). Authenticity and commoditization tourism. Annals of Tourism Research, 15(3), 371-386.

Cohen, E. (2014). Bullfighting and Tourism. Tourism Analysis 19(5): 545-556.

Cohen, E. (2015). Young elephants in Thai tourism: A fatal attraction. In K. Markwell ed. Animals and Tourism. Bristol: Channel View Publications, pp.163-179.

Cohen, E. \& Cohen, S.A. (2012a). Current sociological theories and issues in tourism. Annals of Tourism Research, 39(4), 2177-2202.

Cohen, E. \& Cohen, S.A. (2012b). Authentication: Hot and cool. Annals of Tourism Research, 39(3), 1295-1314.

Cohen, E. \& Cohen, S.A. (2015a). A mobilities approach to tourism from emerging world regions. Current Issues in Tourism, 18(1), 11-43.

Cohen, E. \& Cohen, S.A. (2015b). Beyond Eurocentrism in tourism: A paradigm shift to mobilities. Tourism Recreation Research, 40(2), 157-168.

Cohen, S.A., Duncan, T. \& Thulemark, M. (2015). Lifestyle mobilities: The crossroads of travel, leisure and migration. Mobilities, 10(1), 155-172.

Cohen, S.A., Higham, J.E.S. \& Reis, A.C. (2013). Sociological barriers to developing sustainable discretionary air travel behaviour. Journal of Sustainable Tourism, 21(7), 982-998.

Coles, T. (2015). Tourism mobilities: Still a current issue in tourism? Current Issues in Tourism, 18(1), 62-67.

Conran, M. (2011). They really love me! Intimacy in volunteer tourism. Annals of Tourism Research, 38(4), 1454-1473.

Dann, E. \& Dann, G. M.S. (2012). Sightseeing for the sightless and soundless: Tourism experiences of the deafblind. Tourism, Culture and Communication, 12(2), 125-140.

Dann, G. \&Jacobsen, S. (2003). Tourism smellscapes. Tourism Geographies, 5(1), 3-25.

de Souza Bispo, M. (2016). Tourism as practice. Annals of Tourism Research, 61, 170-179.

d'Heuteserre, A.-M. (2015). Affect theory and the attractivity of destinations. Annals of Tourism Research, 55, 77-89.

Dinhopl, A. \& Gretzel, U. (2016). Selfie-taking as touristic looking. Annals of Tourism Research, 57, 126-139.

Dirksmeier, P. \& Helbrecht, I. (2015). Resident perceptions of new urban tourism: A neglected geography of prejudice. Geography Compass, 9(5), 276-285.

Dixon-Woods, M., Bonas, S., Booth, A., Jones, D.R., Miller, T., Sutton, A.J., Shaw, R.L., Smith, J.A., Young, B. (2006a). How can systematic reviews incorporate qualitative research? A critical perspective. Qualitative Research, 6(1) 27-44. 
Dixon-Woods, M., Cavers, D., Agarwal, S., Annandale, E., Arthur, A., Harvey, J., Hsu, R., Katbama, S., Olsen, R., Smith, L., Riley, R., Sutton, A.J. (2006b). Conducting a critical interpretive synthesis of the literature on access to healthcare by vulnerable groups. $B M C$ Medical Research Methodology, 6(35) 1-13.

Doering, A. \& Duncan, T. (2016). Mobilities for tourism studies and 'beyond': A polemic. Tourism Analysis, 21, 47-59.

Donnelly, J. (1984). Cultural relativism and universal human rights. Human Rights Quarterly, 6(4), 400-419.

Echtner, C.M. \& Prasad, P. (2003). The context of Third World tourism marketing. Annals of Tourism Research, 30(3), 660-682.

Edensor, T. (1998). Tourists at the Taj: Performance and meaning at a symbolic site. London: Routledge.

Fennell, D. (2006). Tourism ethics. Clevedon: Channel View.

Fennell, D. (2015). Akrasia in tourism: Why we sometimes act against our better judgement? Tourism Recreation Research, 40(1), 95-106.

Ferguson, L. \& Alarcón, D.M. (2015). Gender and sustainable tourism: reflections on theory and practice. Journal of Sustainable Tourism, 23(3), 401-416.

Figueroa-Domecq, C., Pritchard, A., Segovia-Pérez, Morgan, N. \& Villacé-Molinero, T. (2015). Tourism gender research: A critical accounting. Annals of Tourism Research, 52, 87103.

Foucault, M. (1976). The birth of the clinic. London: Tavistock.

Franklin, A. (2014). On why we dig the beach: Tracing the subjects and objects of the bucket and spade for a relational materialist theory of the beach. Tourist Studies, 14(3), 261-285.

Franklin, A. \& Crang, M. (2001). The trouble with tourism and travel theory? Tourist Studies, $1(1), 5-22$.

Frazer, R. \& Waitt, G. (2016). Pain, politics and volunteering in tourism studies. Annals of Tourism Research, 57, 176-189.

Frisvoll, S. (2013). Conceptualising authentication of ruralness. Annals of Tourism Research, 43, 272-296.

Gale, T. (2009). Urban beaches, virtual worlds and 'the end of tourism'. Mobilities, 4(1), 119138.

Germann Molz, J. (2013). Social networking technologies and the moral economy of alternative tourism: the case of couchsurfing.org. Annals of Tourism Research, 43, 210-230.

Gibson, C. (2014). Souvenirs, materialities and animal encounters: Following Texas cowboy boots. Tourist Studies, 14(3), 286-301.

Gotham, K.F. (2005). Tourism gentrification: The case of New Orleans' Vieux Carre (French Quarter). Urban Studies, 42(7), 1099-1121. 
Grant, M.J. \& Booth, A. (2009). A typology of reviews: An analysis of 14 review types and associated methodologies. Health Information and Libraries Journal, 26, 91-108.

Griggio, C. (2015). Looking for experience at Vittangi Moose Park in Swedish Lapland. Scandinavian Journal of Hospitality and Tourism, 5(1), 244-265.

Haldrup, M. \& Larsen, J. (2006). Material cultures of tourism. Leisure Studies, 25(3), 275-289.

Hall, C.M. \& Tucker, H. (2004). Tourism and post-colonialism: Contested discourses, identities and representations. Abingdon: Routledge.

Hannam, K., Sheller, M., \& Urry, J. (2006). Editorial: Mobilities, immobilities, moorings. Mobilities, 1(1), 1-22.

Harwood, S. \& El-Manstrly, D. (2012). The performativity turn in tourism. University of Edinburgh Business School Working Paper Series, vol. 12/05, University of Edinburgh Business School.

Heyes, C.J. (2007). Self-transformations: Foucault, ethics and normalized bodies. Oxford: Oxford University Press.

Holland-Wade, G. (1998). A concept analysis of personal transformation. Journal of Advanced Nursing, 28(4), 713-719.

Jóhannesson, G.T., Ren, C. \& van der Duim, R. (2015). Tourism encounters and controversies: Ontological politics of tourism development. Farnham: Ashgate.

Hooper, D., Costley, C.L. \& Friend, L.A. (2015). Embodied self-authentication. Australasian Marketing Journal, 23, 319-324.

Hultén, B. (2011). Sensory marketing: The multi-sensory brand-experience concept. European Business Review, 23(3), 256-273.

Jacobsen, J.K.S. (2014). Beyond the gaze: Tourist experiences with senses other than sight. Session, XVIII ISA World Congress of Sociology, Yokohama, 17 July 2014.

Jensen, M.T. (2016). Hypersensitive tourists: The dark sides of the sensuous. Annals of Tourism Research, 57, 239-242.

Jensen, M.T., Scarles, C. \& Cohen, S.A. (2015). A multisensory phenomenology of interrail mobilities. Annals of Tourism Research, 53, 61-76.

Jóhannesson, G.T. (2005). Tourism translations: Actor-network theory and tourism research. Tourist Studies, 5(2), 133-150.

Kim, J.J. \& Fesenmaier, D.R. (2015). Designing tourism places: Understanding the tourism experience through our senses. Tourism Travel and Research Association: Advancing Tourism Research Globally. Paper 19.

Kirilova, K., Lehto, X.Y. \& Cai, L. (2016). Tourism and existential transformation: An empirical investigation. Journal of Travel Research, doi: 10.1177/0047287516650277.

Knani, M. (2014). Ethics in the hospitality industry: Review and research agenda. International Journal of Business and Management, 9(3), 1-8. 
Knudsen, B. T., \& Waade, A. M. (2010). Performative authenticity in tourism and spatial experience: Rethinking the relation between travel, place and emotion. In B. T. Knudsen \& A. M. Waade (Eds.), Re-investing authenticity: Tourism, place and emotions (pp. 1-19). Bristol: Channel View Publications.

Lamers, M., van der Duim, R. \& Spaargaren, G. (2017). The relevance of practice theories for tourism research. Annals of Tourism Research, 62, 54-63.

Lamont, M. (2014). Authentication in sports tourism. Annals of Tourism Research, 45, 1-17.

Latour, B. (2005). Reassembling the social. Oxford: Oxford University Press.

Lean, G.L. (2012). Transformative travel: A mobilities perspective. Tourist Studies, 12(2), 151172.

Lean, G., Staiff, R. \& Waterton, E. (2014). Travel and transformation. Farnham: Ashgate.

Lee, A.H., Guillet, B.D. \& Law, R. (2016). Tourists' emotional wellness and hotel room colour. Current Issues in Tourism, doi: 10.1080/13683500.2016.1217830.

Li, S., Scott, N. \& Walters, G. (2015). Current and potential methods for measuring emotion in tourism experiences: a review. Current Issues in Tourism, 18(9), 805-827.

Liu, A.-L., Liu, F.-C. \& Deng, Z.-Y. 2016. Review of soundscape studies in tourism. Tourism Tribune, 31(3), 114-126.

Lovelock, B. \& Lovelock, K.M. (2013). The ethics of tourism: Critical and applied perspectives. London: Routledge.

Lugosi, P. (2016). Socio-technological authentication. Annals of Tourism Research, 58, 100113.

Luzecka, P. (2016). 'Take a gap year!' A social practice perspective on air travel and potential transitions towards sustainable tourism mobility. Journal of Sustainable Tourism, 24(3), 446462.

Lyotard, J-F. (1979). The postmodern condition: A report on knowledge. Manchester: Manchester University Press.

Ma, J., Gao, J., Scott, N. \& Ding, P. (2013). Customer delight from theme park experiences. Annals of Tourism Research, 42, 359-381.

MacCannell, D. (1973). Staged authenticity: Arrangements of social space in tourist settings. The American Journal of Sociology, 79(3), 589-603.

MacCannell, D. (1976). The tourist: A new theory of the leisure class. New York: Schocken Books.

MacCannell, D. (2011). The ethics of sightseeing. Berkeley: University of California Press.

Masson, A. (2016). Handicap sensorial \& tourisme: handicap visual ou auditif: des deficiences mal connues du monde du tourisme. Espaces, Tourisme \& Loisirs, 328, 14 -67.

Matteucci, X. and Filep, S. 2015. Eudaimonic tourist experiences: The case of flamenco. Leisure Studies, doi.org/10.1080/02614367.2015.1085590. 
Mkono, M. (2013). Hot and cool authentication: A netnographic illustration. Annals of Tourism Research, 41, 215-218.

Modlin, E. A., Alderman, D. H., \& Gentry, G. W. (2011). Tour guides as creators of empathy: The role of affective inequality in marginalizing the enslaved at plantation house museums. Tourist Studies, 11(1), 3-19.

Mol. A. (1999). Ontological politics: A word and some questions. Sociological Review, 47(S1), 74-89.

Mostafanedzad, M. \& Hannam, K. (2014). Moral encounters in tourism. Farnham: Ashgate.

Muecke, S. \& Wergin, C. (2014). Materialities of tourism in the twenty-first century: A very brief introduction. Tourist Studies, 14(3), 227-230.

Nicolini, D. (2012). Practice Theory, Work, \& Organization: An Introduction. Oxford: Oxford University Press.

Noy, C. (2009). The politics of authenticity in a national heritage site in Israel. Qualitative Sociology Review, 5(1), 112-129.

Ocha, W. \& Earth, B. (2012). Identity diversification among transgender sex workers in Thailand's sex tourism industry. Sexualities, 16(1/2), 195-216.

Pearce, P. (2012). The experience of visiting home and familiar places. Annals of Tourism Research, 39(2), 1024-1047.

Pfaff, J. (2010). A mobile phone: mobility, materiality and everyday Swahili trading practices. Cultural Geographies, 17(3), 341-357.

Picard, D. \& Robinson, M. (2012). Emotion in Motion: Tourism, Affect and Transformation. London: Routledge.

Pocock, N. (2015). Emotional entanglements in tourism research. Annals of Tourism Research, $53,31-45$.

Pons, P.O. (2003). Being-on-holiday: Tourist dwelling, bodies and place. Tourist Studies, 3(1), 47-66.

Pons, P.O. (2009). Building castles in the sand: Repositioning touch on the beach. The Senses and Society, 4(2), 195-210.

Pritchard, A., Morgan, N. \& Ateljevic, I. (2011). Hopeful tourism: A new transformative perspective. Annals of Tourism Research, 38(3), 941-963.

Pritchard, A., Morgan, N., Ateljevic, I. \& Harris, C. (2007). Tourism and gender: Embodiment, sensuality and experiences. Wallingford: CABI.

Pritchard, A. \& Morgan, N. (2011). Tourist bodies, transformation and sensuality. In P. Bramham and S. Wagg eds. The new politics of leisure and pleasure. Basingstoke: Palgrave Macmillan.

Rakić, T. \& Chambers, D. (2012). Rethinking the consumption of places. Annals of Tourism Research, 39(3), 1612-1633. 
Rantala, O. (2010). Tourist practices in the forest. Annals of Tourism Research, 37(1), 249264.

Reisinger, Y. (2015). Transformational tourism: Host perspectives. Wallington: CABI.

Reisinger, Y. \& Steiner, C.J. (2006). Reconceptualizing object authenticity. Annals of Tourism Research, 33(1), 65-86.

Rickly-Boyd, J.M. (2012). Lifestyle climbing: Toward existential authenticity. Journal of Sport and Tourism, 17(2), 85-104.

Rickly-Boyd, J.M., Knudsen, D.C., Braverman, L.C. \& Metro-Roland, M.M. (2014). Tourism, Performance and Place: A geographic perspective. New York: Routledge.

Robledo, M.A. \& Batle, J. (2015). Transformational tourism as a hero's journey. Current Issues in Tourism, doi.org/10.1080/13683500.2015.1054270.

Quan, S. \& Wang, N. (2004). Towards a structural model of the tourist experience: an illustration from food experiences in tourism. Tourism Management, 25(3), 297-305.

Schatzki, T. R., Cetina, K.K. \& von Savigny, E. (2001). The Practice Turn in Contemporary Theory. London: Routledge.

Sheller, M. \& Urry, J. (2006). The new mobilities paradigm. Environment and Planning A, $38(2), 207-226$.

Shepherd, R.J. (2015). Why Heidegger did not travel: Existential Angst, authenticity and tourist experiences. Annals of Tourism Research, 52, 60-71.

Shoval, N. \& Ahas, R. (2016). The use of tracking technologies in tourism research: the first decade. Tourism Geographies, doi: 10.1080/14616688.2016.1214977.

Sim, S. (2011). The Lyotard Dictionary. Edinburgh: Edinburgh University Press

Small, J., Darcy, S. \& Packer, T. (2012). The embodied tourist experiences of people with vision impairment: Management beyond the visual gaze. Tourism Management, 33(4), 941950.

Steiner, C.J. \& Y. Reisinger (2006). Understanding existential Authenticity. Annals of Tourism Research 33(2), 299-318

Spracklen, K., Laurencic, J. \& Kenyon, A. (2013). 'Mine's a Pint of Bitter': Performativity, gender, class and representations of authenticity in real ale tourism. Tourist Studies, 13(3), 304321.

Swain, M.B. (1995). Gender in tourism. Annals of Tourism Research, 22(2), 247-266.

Tribe, J. (2009). Philosophical issues in tourism. Bristol: Channel View.

Tucker, H. (2016). Empathy and tourism: Limits and possibilities. Annals of Tourism Research, $57,31-43$.

Tung, V. W. S., \& Ritchie, J. R. B. (2011). Exploring the essence of memorable tourism experiences. Annals of Tourism Research, 38(4), 1367-1386. 
Uriely, N. (2005). The tourist experience: Conceptual developments. Annals of Tourism Research, 32(1), 199-216.

Urry, J. (1990). The tourist gaze: Leisure and travel in contemporary societies. London: Sage. Urry, J. (1995). Consuming Places. London: Routledge.

Urry, J. (2000). Mobile sociology. British Journal of Sociology, 51(1), 185-203.

van der Duim, R., Ren, C. \& Jóhannesson, G.T. (2013). Ordering, materiality, and multiplicity: Enacting Actor-Network Theory in tourism. Tourist Studies, 13(1): 3-20.

van der Duim, R., Ren, C. \& Jóhannesson, G.T. (2017). ANT: A decade of interfering with tourism. Annals of Tourism Research, 64, 139-149.

Vaninni, P., Waskul, D. \& Gottschalk, S. (2011). The senses in self, society and culture: A sociology of the senses. New York: Routledge.

Veijola, S. \& Jokinen, E. (1994). The body in tourism. Theory, Culture and Society, 11, 125151.

Wang, N. (1999). Rethinking authenticity in tourism experience. Annals of Tourism Research, 26(2), 349-370.

Weeden, C. \& Boluk K. (2014). Managing ethical consumption in tourism. Abingdon: Routledge.

Winter, T. (2009). Asian tourism and the retreat of anglo-western centrism in tourism theory. Current Issues in Tourism, 12(1), 21-31.

Xie, P. F. (2011). Authenticating ethnic tourism. Bristol: Channel View Publications.

Yang, E.C.L., Khoo-Lattimore, C. \& Arcodia, C. (2016). A narrative review of Asian female travellers: Looking into the future through the past. Current Issues in Tourism, doi.org/10.1080/13683500.2016.1208741. 